\title{
Operation Nightingale: The Role of BMH Dharan Following the 1988 Nepal Earthquake, and Some Observations on Third World Earthquake Disaster Relief Missions
}

\author{
Lt Col P J Guy \\ FRCS(Ed), RAMC, Consultant Surgeon \\ BMH Hannover, BFPO 33 \\ Major $\mathrm{N}$ Ineson \\ MRCP, RAMC, Consultant Physician \\ BMII Hong Kong, BFPOI
}

Major R Bailie

FFARCS, RAMC, Senior Specialist in Anaesthetics

$B M H$ Dharan, BFPO 4

\section{Major A Grimwood}

QARANC, Matron

BMH Berlin, BFPO 45

\begin{abstract}
SUMMARY: Following a large earthquake in Nepal, the experience of a small hospital in dealing with the resulting ri⿱乛⿻ casualties is described. The value of pre-planning and effective triage of the injured is stressed, and aspects of surge and medical care specific to earthquake victims discussed. Clinical and administrative challenges encountere 8 mounting a major relief exercise in a Third World setting are also described. The frequent exercising of military hosp and personnel in handling mass casualties is as applicable to civilian natural catastrophies as to battlefield megce support.
\end{abstract}

\section{Introduction}

The British Military Hospital (BMH) in Dharan is an 80 bed static acute unit located in a military cantonment in East Nepal. It provides specialist facilities to local civilians as well as British Gurkha personnel. The town of Dharan (pop approx 100,000) lies in an carthquake zone where the Indo-Australian plate subducts the Tibetan Plateau ${ }^{1}$, and the single storey military hospital is designed to withstand major tremors. At 0450 hrs on 21 August 1988, an earthquake measuring 6.7 on the Richter scale, lasting about 40 seconds, devastated parts of the town of Dharan and many hill villages in East Nepal (Fig 1). Seven hundred and fifteen people were killed, 1,135 injured, and about 18,000 dwellings were destroyed or damaged.

The major accident plan for BMH Dharan was activated within an hour of the earthquake, and the hospital played a key role during the ensuing weeks in the provision of specialist care for the injured.

During "Operation Nightingale", the official British response to the disaster, aid in many forms was channelled through HQ British Gurkhas Nepal. This paper deals specifically with medical aspects of the relief exercise.

\section{Effects of the Earthquake}

Throughout the affected area most single storo concrete buildings other than those engulfed landslides survived intact, as did houses constructed $\mathbb{D}$. wood. Many multi-storey blocks suffered damage, a $\vec{\pi}$ the large majority of dwellings constructed of brick a clay-mortar (adobe) collapsed, entombing the occupants. A late monsoon deluge hampered resc $\overrightarrow{\mathbb{P}_{2}}$ work and prevented helicopter evacuation from to hills. Roads and tracks were disrupted by landslide: Therefore the normally prolonged business of extractifing earthquake victims from their homes was complicate्ल by poor communications, leading to considerable dela@s before many patients received proper treatment. TF earthquake caught many victims attempting to esca from their beds. Collapsing ceilings accounted for manू axial skeletal injuries, pelvic and lower limb fractures 윽

\section{The Response of BMH Dharan}

At the time of the earthquake, the nornml complement of staff (Table 1) was augmented by을 visiting Army dentist and 3 medical students on temporary attachment. The wives of serving British personnel on the camp provided one additional doct 

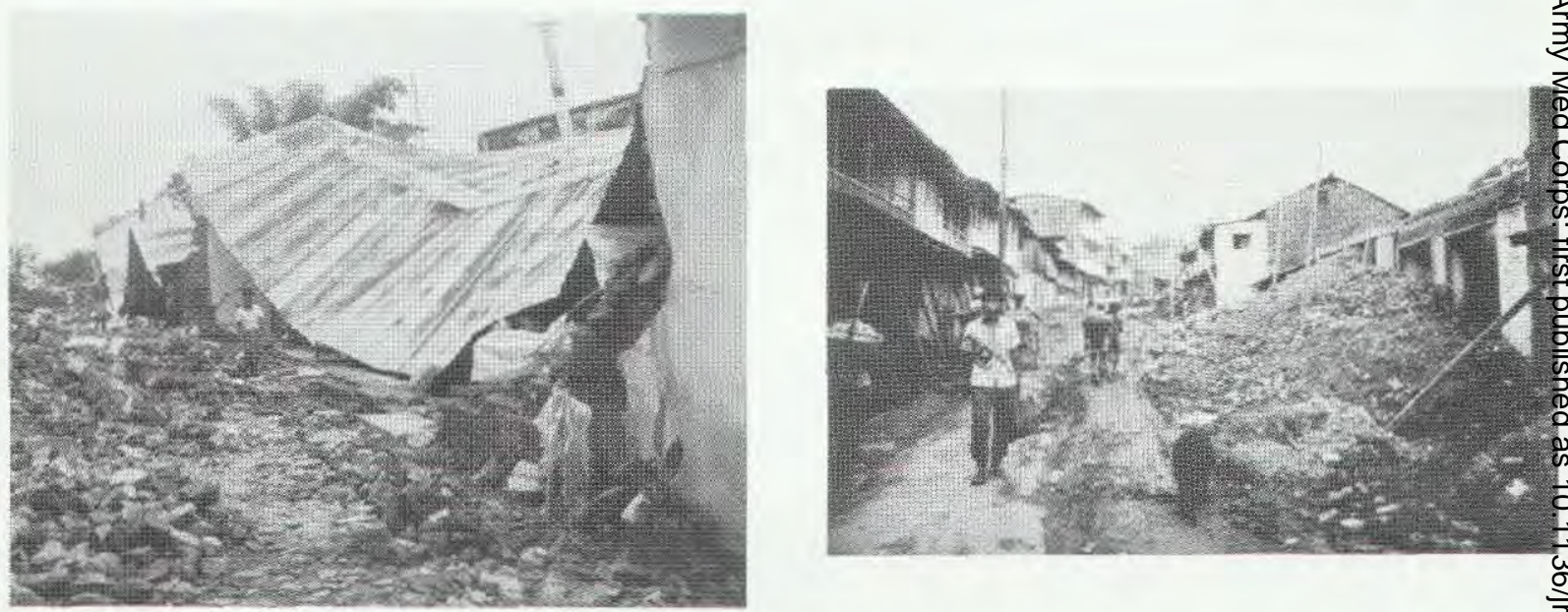

Fig 1. Selective earthquake damage in Dharan. Note the relative vulnerability of adobe buildings and stability of woode席 structures.

Table 1

\section{BMH Dharan staffing for Operation Nightingale}

\begin{tabular}{lcc}
\hline & $\begin{array}{c}\text { Qualified Staff } \\
\text { complement at } \\
\text { time of earthquake } \\
\text { (80 beds) }\end{array}$ & $\begin{array}{c}\text { UK } \\
\text { reinforcing } \\
\text { staff } \\
\text { (212 beds) }\end{array}$ \\
\hline General Duties MOs & 1 & 2 \\
Physicians & 1 & 1 \\
Anaesthetists & 1 & 2 \\
Surgeons & 1 & 4 \\
Gynaccologists & - & 2 \\
Nurses (RGN \& ENG) & 2 & 38 \\
Midwives & - & 4 \\
Technical \& paramedical & 4 & 7 \\
Medical assistants (CMT) & - & 10 \\
Administrators & 1 & 1 \\
& - & - \\
& 19 & 75 \\
\hline
\end{tabular}

a radiographer and 7 nurses. For the first 48 hours, this ad hoc team of regular and volunteer staff, assisted by Nepali medical orderlies and technicians, produced the most significant medical relief effort in East Nepal, and provided the only sophisticated surgical facility.

After opening a Casualty Clearing Station (Fig 2a \& b), the hospital was progressively expanded to 212 beds in tented wards, and a separate medical refugee centre was established in a large hall. This provided accommodation for those patients and a few relatives whose homes had been destroyed, and who required some form of ongoing treatment. At its peak 10 days after the earthquake, 157 individuals were being cared for in the refugee centre.
Specialist medical teams from Hong Kong and the UK reinforced the hospital, bringing orthopaedic, an thetic and nursing expertise to run a sophistica巴 surgical, obstetric and intensive care service? Enhancement of accommodation with supplies $\vec{D} \vec{f}_{1}$ electricity and water (Fig 3) allowed a reasona㡟 normal level of ward activity to take place.

Although the existing major accident plan invaluable in the carly response, the scale of the disase required considerable support from Headquartô British Gurkhas Nepal, and from the Army's reinfor infra-structure. Effective leadership at all levels, an seemingly infallible resupply chain, were the hallma of success.

\section{Patients}

Eight hundred and eighty-eight victims were treate in the casualty clearing station (CCS) (Fig 2a \& b) befor it closed, 18 days after the earthquake. Two hundre and sixty were admitted, and 628 treated as outpatients? A resumé of injuries leading to admission is given î Table 2. Four hundred and fifty patients were triaged ir the CCS on the first day, and many more with mino injuries received first aid and were discharged withous documentation. Eighty-nine of the most seriousig injured were admitted. One was dead on arrival, on died in the CCS of presumed massive intra-peritonea bleeding, and 8 patients subsequently died in hospital a a result of their injuries (Table 3). One hundred an£ seventy-five operative surgical procedures wer performed on earthquake victims, and an additional 15 오 manipulations of fractures were carried out (Table 4) Many patients required multiple procedures. Twentyㅡㅡㄹ. seven emergency operations were carried out on the firsin day.

When maternity services in Dharan became paralyse

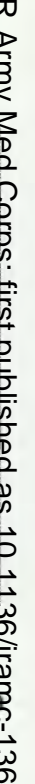




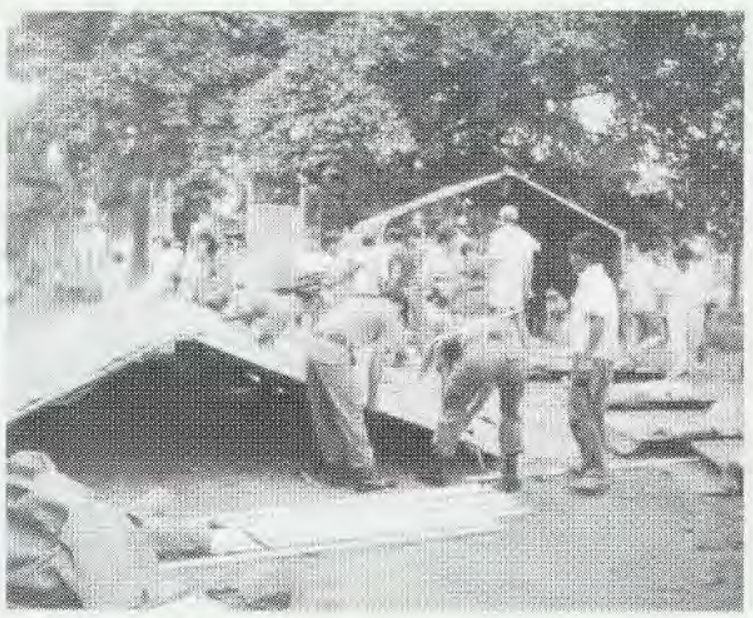

Fig 2a. Casualty Clearing Station (CCS) being constructed.

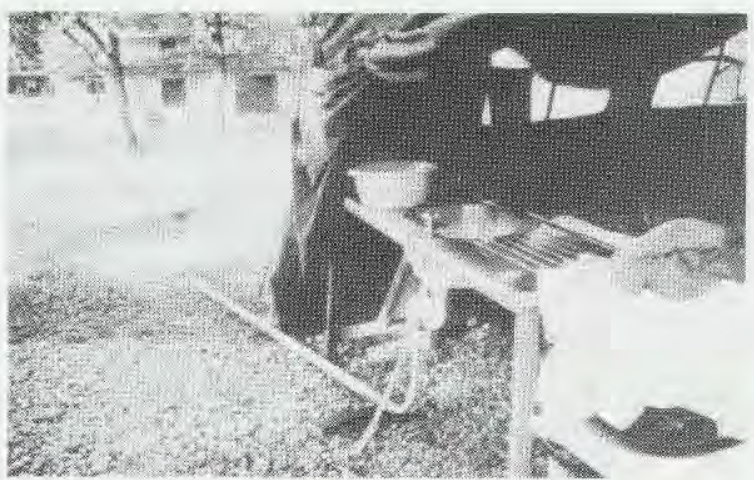

Fig 3. Sinks, gravity fed from storage bowsers, and electric lighting allowed near normal ward activities in tented

Table 2

Earthquake injuries leading to admission

\section{FRACTURES}

Lower Limb: Femur

Tibia

Pelvis

Spine

Upper Limb

2. Crush chest and rib fractures

3. Head injury

4. Abdominal trauma

5. Severe soft tissue injury

6. Established tetanus

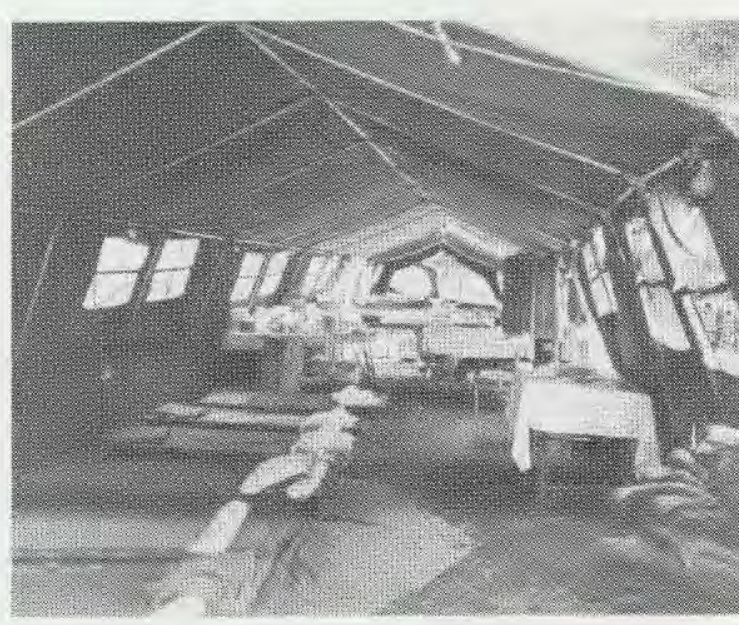

Fig 2b. Completed CCS prior to opening.

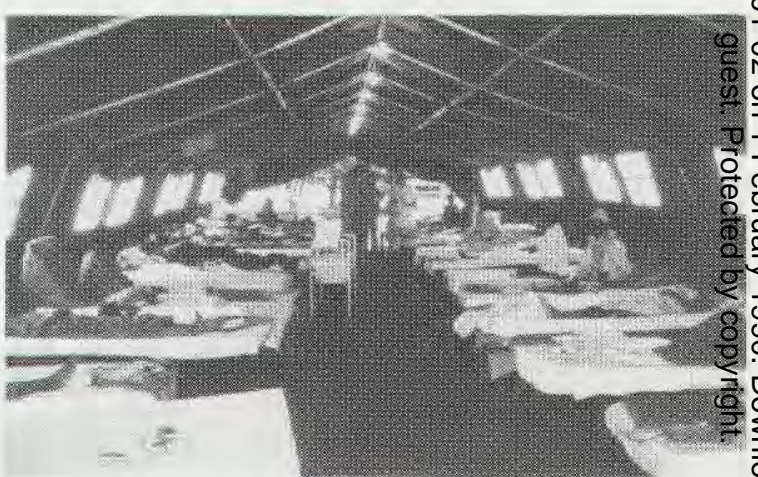

\section{accommodation.}


Table 4

Operations on earthquake victims

(to 30.09.88)

Wound excision and debridement

55

Skin graft

Rotation flaps

Drainage of abscess

MUA fractures, and/or POP application

Application of skeletal traction

Open fracture reduction: Internal fixation

External fixation

$\mathrm{C} 1 / \mathrm{C} 2$ fusion

Amputations: Legs

Fingers \& toes

Laparotomy for visceral damage

Suprapubic cystostomy, or repair ruptured urethra

Tracheostomy

Feeding gastrostomy

Others

Total procedures

due to structural damage to the local hospital, the BMH provided obstetric care for the civilian population on demand. This considerably increased the number of unbooked and complicated deliveries (Table 5).

\section{Discussion}

\section{Surgical Considerations}

The majority of victims who survived the earthquake did not sustain injuries that posed an immediate threat to life, and surgery performed during the first 24 hours was restricted to the management of the most severely injured (27/450). During this phase, surgical treatment consisted of measures to control severe haemorrhage or

\section{Table 5}

Obstetric deliveries, BMH Dharan. 25.8.88-30.9.88

\begin{tabular}{lcc}
\hline & $\begin{array}{c}\mathbf{2 5 . 8 . 8 8} \\
\text { to } \\
\mathbf{3 0 . 9 . 8 8}\end{array}$ & $\begin{array}{c}\text { Preceding } \\
\text { 3-year average } \\
\text { for period }\end{array}$ \\
\hline $\begin{array}{l}\text { All deliveries } \\
\% \text { unbooked cases }\end{array}$ & 101 & 37 \\
$\%$ stillbirths \& & $69 \%$ & $3.4 \%$ \\
perinatal deaths & $7 \%$ & $3.5 \%$ \\
$\%$ babies $<2.5 \mathrm{Kg}$ & $9 \%$ & $4.2 \%$ \\
$\%$ ruptured uterus & $3 \%$ & - \\
$\%$ PPH $>500 \mathrm{mls}$ blood & $7 \%$ & $3.0 \%$ \\
\hline
\end{tabular}

to repair visceral damage, including bladder an urethral injuries secondary to major pelvic fracture Additionally, debridement of severely contaminate $\mathbf{Z}$ wounds and manipulation of badly displaced fracture $\mathbb{\Omega}$ with or without the application of external fixators, w: regarded as a relative emergency. The Army's battl음 field external fixator (Centrafix, Central Orthopaedies Ltd) proved extremely versatile and simple to use in th: management of 12 patients, some with devastation injuries (Fig $4 a, b$ \& c). We are not aware of any previoio reports of its use in civilian casualties. However, relatively low cost and versatility make it ideal for use the management of the large number of open contan inated fractures which occur during an earthquake. T1ळ high incidence of spinal, pelvic and lower limb fracture $\overrightarrow{0}$ complicated by severe soft tissue injuries, highlights thie compelling need to include well equipped orthopaed $\vec{\omega}$ teams in medical rescue missions to earthquake disast areas. They should include physiotherapists and othe $\vec{?}$ skilled in rehabilitation. Paraplegic patients, howeve face an uncertain future in the third world, particular $\frac{1}{6}$ in the Himalayan foothills.

An increase in complicated obstetric deliveries 요 BMH Dharan, especially the sudden arrivale unbooked cases in advanced stages of labour (Table⿻ created an additional burden on already overworkez staff. Somewhat unorthodox deliveries were recor on rickshaws and outside the physician's office. T) arrival of an obstetric team among the reinforcem proved of unexpected value in an earthquake crisis.

\section{Anaesthetic considerations}

Prior to resuscitation, many patients, especially t\$ with serious abdominal, pelvic and lower limb injug had suffered considerable blood and other fluid lossc This was compounded by dehydration secondary delayed rescue and prolonged transportation hospital. All patients with clinical shock, dehydrati and established myoglobinuria, or those considered risk of developing crush syndrome, were given liber quantities of crystalloid with colloid supplementation required. Whole blood was only used to corre significant anaemia or per-operative losses, surprising little being required overall. Of 697 units obtained (5) imported, 197 locally bled donors), 470 were cros matched for 176 patients. Only 252 of the 697 units blood were eventually used for the earthquake victim This low usage rate has been noted by others ${ }^{2}$.

No patient died from hypovolacmia after admissio and only one developed (and later died from) reng failure secondary to crush syndrome. This contrasts wi other earthquake experiences ${ }^{3.4}$ where the syndrome o reported in $3.5 \%$ of all victims, and up to $36 \%$ of tho with fractured long bones. No facilitics for haem dialysis or filtration existed in Nepal at the time of th earthquake. Chest infections were common, and one ? year old male with chest injuries and multiple fractur 


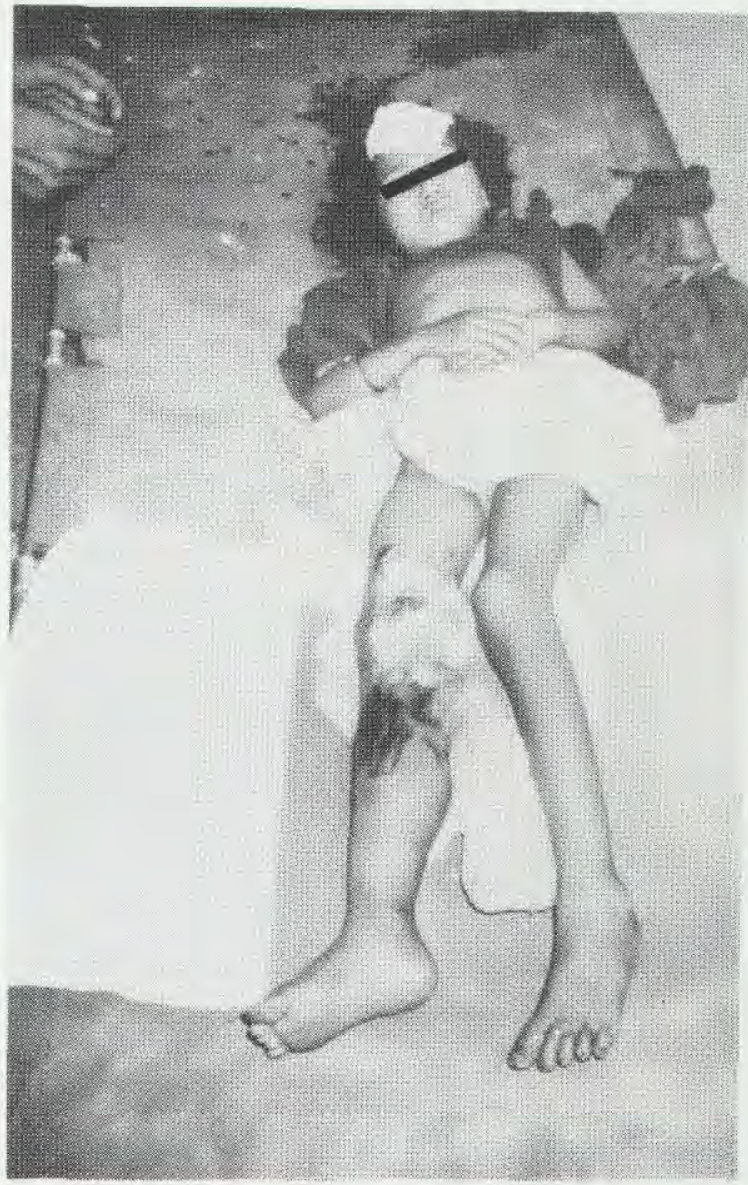

Fig 4a. 11 year old girl admitted 8 days after the

earthquake, with a compound fracture of the upper tibia and extensive soft tissue injury.
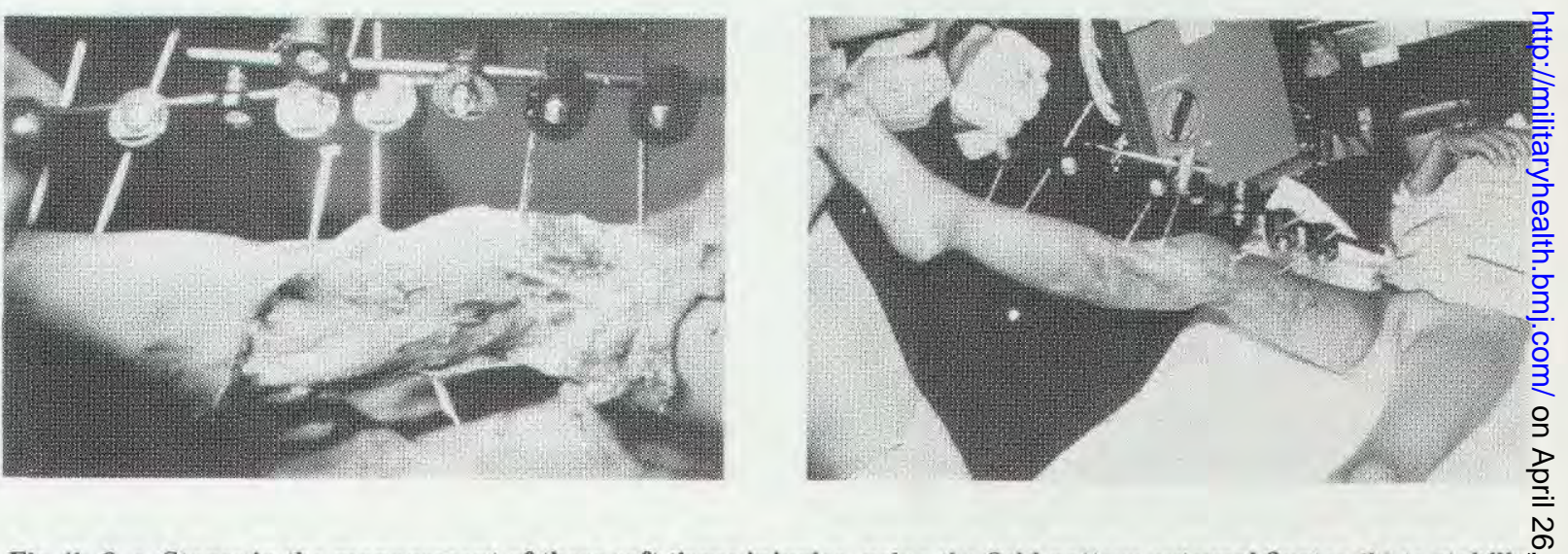

Fig $4 b$ \& c. Stages in the management of these soft tissue injuries, using the field pattern external fixator (b) to stabilizo the underlying fracture. Immediately prior to skin grafting (c), 
died from post traumatic respiratory insufficiency.

Any anaesthetic team working in the Third World must be prepared for a lack of anaesthetic carrier gases, including oxygen. Late monsoon flooding in the wake of the earthquake disrupted the re-supply of bottled gases for over two weeks. This problem was overcome by the extensive use of the British Tri-Service pattern anaesthetic equipment, with supplemental oxygen provided by an electrically powered oxygen concentrator. Used in conjunction with the Cape TC50, an electric ventilator, the combined equipment (Fig 5) provided an extremely satisfactory and safe means of anaesthesia for all types of surgery. Any anaesthetic plan in such situations should provide for "draw-over" anaesthesia, oxygen concentrators and an independent electrical power supply.

Our experience identified the need to provide some form of high dependency or intensive care unit (ICU). Twenty-eight patients, including 6 on long-term ventilation, required this facility. The Cape TC50 and

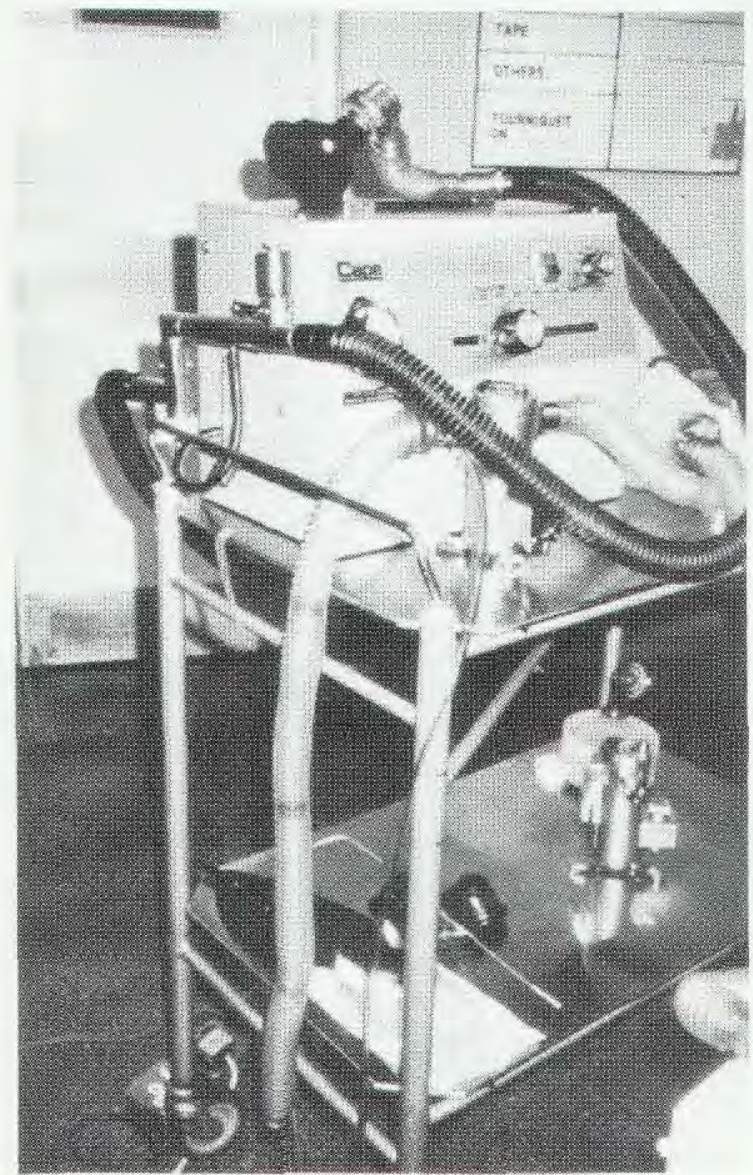

Fig 5. Cape TC 50 and Tri-Service field anaesthetic equipment. oxygen concentrators again proved invaluable a reliable in this situation, although power failure to ventilator contributed to 2 deaths. An apnoea ala min fitted to the TC50 is strongly recommended. Intens 8 e care is costly in both manpower and materiel, ad benefits must be carefully assessed. However, there Pिa definite place for such units in the management 4 f earthquake victims, especially if haemodialysis is to performed.

\section{Role of the physician}

The requirement to separate the Triage area frgm Resusciation following an earthquake is explained later. There is a compelling need to co-ordinate the activitRs of both units, and when surgical teams are tied up in $\overrightarrow{\mathrm{f}}$ e operating theatre and where there is no senior accidopit and emergency specialist, the physician plays a v $\mathrm{v}$ administrative and clinical role. In the major accide plan for BMH Dharan, the physician is tasked resuscitation and triage officer, and the use of physici.js in this role in major disasters has been reportod elsewhere ${ }^{5}$.

We found that earthquake victims were partic क्षि ते prone to develop severe chest infections, probablo to a combination of pre-existing lung disease, crutolred thoracic cage, dust inhalation, and anaesthetio 궁 irritation. The physician plays an important role iq $\mathbb{Q}_{\mathrm{i}} \mathrm{e}$ management of these gravely ill patients, especiag the intensive care unit.

In the context of preventive medicine, and is $\vec{b}_{\mathrm{c}}$ absence of any effective local public health laboro facilities, we found that the physician was influentigs head of an environmental health team, especia monitoring the local water supplies and in formulating vaccination policy. Initially, the coliform colony cognt in town tapwater was in excess of 1000 per $100 \mathrm{mls}$, . రి after decisive action by the environmental health team, hyperchlorination reduced this to a consistently $\overline{\mathbf{Q}}_{\mathrm{g}} \mathrm{w}$ level. One thousand eight hundred and twenty-seren military and key civilian personnel were vaccinat mainly against cholera and typhoid. No cases we ke subsequenty reported in Dharan, though both $\overline{\text { B: }}$ : common in the region. There was no reported incre in the incidence of any communicable disease follow the earthquake, a finding confirmed previously $y^{6.7}$.

After the earthquake, a large number of patients la returned with uncontrolled diabetes, hypertensig, heart failure and tuberculosis, resulting from ti] inability to reach out-patient clinics, or obtain resupp gies of their medications. Physicians can expect busy clirics and increased admissions after disrupted communiôtions have been restored.

\section{Nursing considerations}

The admission of 89 badly injured patients in the fost 14 hours following the earthquake proved Na considerable nursing challenge. Twenty-eight of the 
least severely ill existing patients had to be discharged, and 46 additional camp beds and litters were placed on verandahs and in tents to make room for new admissions. After initial deployment to the Casualty Clearing Station and Resuscitation, trained staff were supplemented on the wards by camp volunteers, as the huge problem of ward administration became apparent. Several Nepali nursing and paramedical staff lost their own homes or possessions as a result of the earthquake (Fig 6), yet none missed a day's work.

Earthquake victims are difficult and labour intensive patients to nurse. Most were covered in dust and rubble on admission, and all required routine bathing, delousing and de-worming. Nearly all had severe soft tissue wounds and multiple fractures, and many were paraplegic or had visceral injuries. Twenty-seven required post-operative monitoring on the first day.

This period of intense activity followed the frightening personal experience of a dramatic earthquake, and it is remarkable that few staff displayed any serious stress reactions. Throughout the relief exercise, trained nursing staff frequently worked in an "extended role", undertaking many duties normally performed by junior doctors. However, after the initial excitement of the earthquake, nursing tasks became physically tiring, unglamorous and emotionally taxing, especially for reinforcements unacclimatized to tropical monsoon conditions and unaccustomed to the cultural deprivation of Dharan.

Re-evaluation of needs and re-deployment of staff was required at least every day, and the value of regularized working shifts was quickly recognised, especially for local staff. A good "Matron" is invaluable in a disaster relief team, and nursing administration must be sensitive to the fact that stress amongst staff in such conditions can lead to decompensation.

\section{Administrative considerations}

The initiation and co-ordination of the major accident plan was followed by an urgent re-assessment of the requirement for materiel and personnel reinforcement. This proved particularly difficult, since there was no indication of the scale of the disaster in the Himalayan foothills, and estimation of the likely number of casualties was almost impossible. The expansion of existing hospital facilities and the creation of a medical refugee centre required careful planning, and as the National response became more co-ordinated, close liaison with the press, local politicians and senior civilian medical personnel proved very time consuming. This was not infrequently to the detriment of other clinical and administrative duties. A multitude of new problems arose daily, mostly relating to personnel or materiel reinforcement, or to patient welfare. Six hundred and six "immediate" or "priority" telegraphic signals relating directly to Operation Nightingale alone were sent from the Administrative Office between 21 August and 30 September. The administrative and personnel officers played a vital role in co-ordinating the response and in handling the many problems that arose among reinforcing staff.

Daily meetings between the various heads of departments of HQ British Gurkhas Nepal (Fig 7) were crucial the resolution of both clinical and administrative problems. No clinician should under-estimate the value of such meetings in time of crisis, nor is there a time of greater need for decisive administration in all departments.

\section{General}

Although considerable technological advances have been introduced in Kathmandu hospitals in recent years, as in many developing countries, outside the capital lack of funds has precluded allocation of resources to rural hospitals to similar high standards. The staff of these hospitals work long hours and are unable to get the training needed to raise their standards to those of more

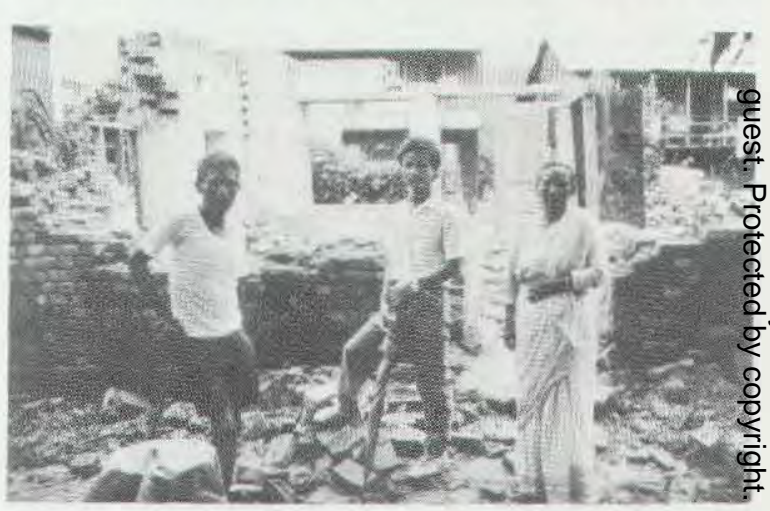

Fig 6. A Nepali operating theatre technician stands with his family in the ruins of his home.

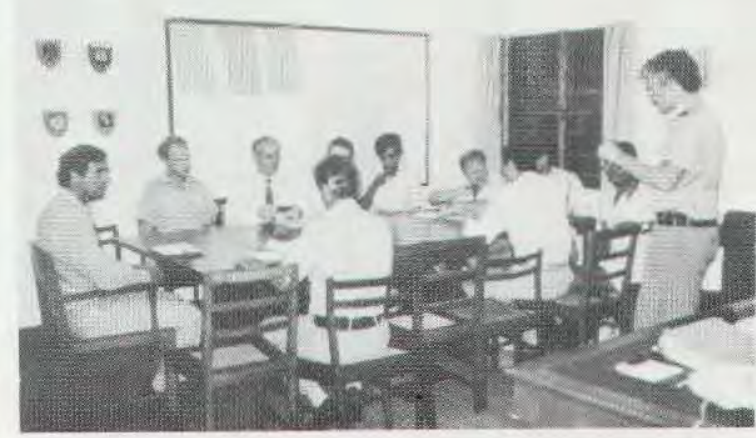

Fig 7. Heads of Departments meet daily under the chairmanship of the acting Commander, British $N$ Gurkhas Nepal. 
sophisticated centres. Apparently little pre-planning for major disasters had been possible, and therefore the initial medical response to the earthquake was somewhat disordered and at times ineffective. We found that volunteer and drafted medical personnel who first arrived in support of local hospitals were also poorly equipped, and that treatment delivered to the injured was occasionally inappropriate. Primary suture of severely contaminated wounds was the most common technical fault (Fig 8), and initially, little attention was paid to tetanus prophylaxis or adequate fracture splinting. This resulted purely from lack of the most basic resources, and reflects the degree of poverty in much of Nepal.

Mahoney, reviewing the design of disaster medical carc systems, stressed the importance of both

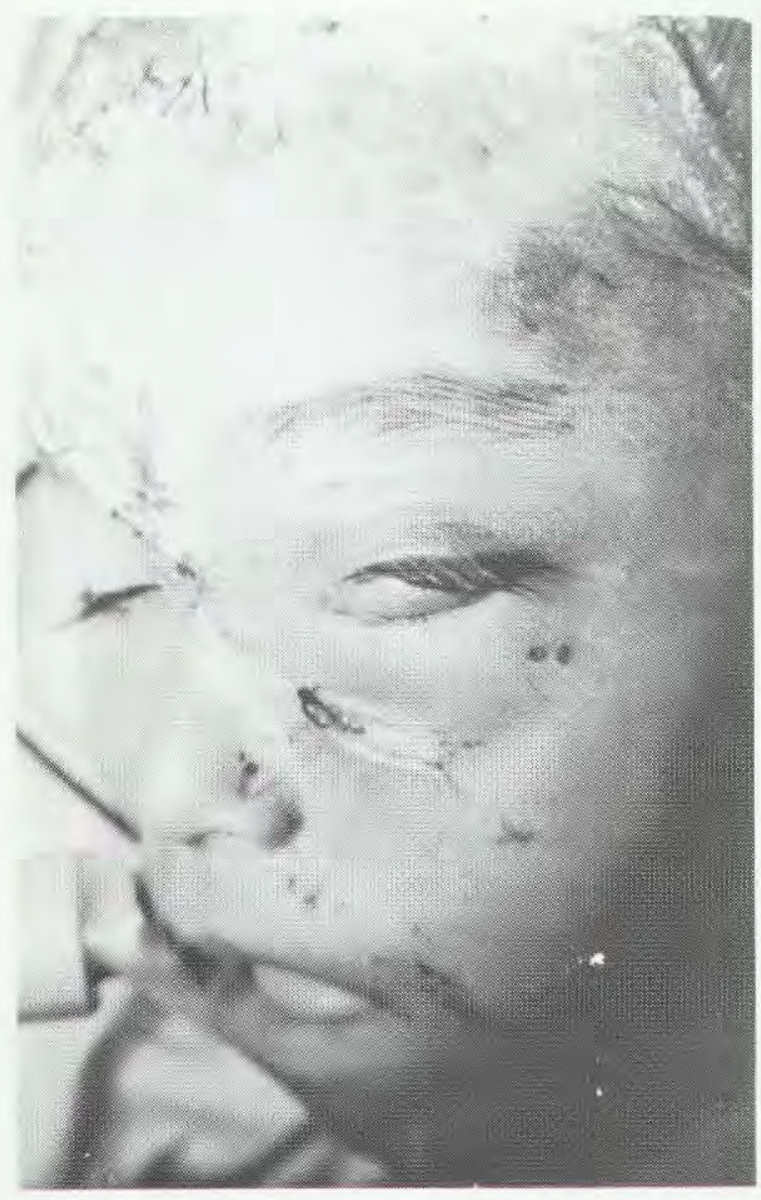

Fig 8.8 year old girl, with a massive, contaminated, primary sutured cranio-facial wound. Discharged with a healed wound, 10 days after re-exploration and enucleation of left eye, and removal of cement debris from the orbital roof. "timeliness" and "appropriateness" of aid. He als noted that well-meaning individuals often flock disaster areas, frequently with little effect. Improve $\mathbb{R}$ communications and co-ordination ${ }^{9}$ and the inclusion $\mathbb{8}$ sophisticated surgical facilities in disaster relief teams $\delta$ have been called for to improve the quality of respons to requests for assistance.

In stark contrast to local facilities, the Casualt $\overrightarrow{F_{0}}$ Clearing Station at the British camp was up and running within 90 minutes of the earthquake. Although limite first aid, resuscitation and holding facilities wer provided here, more definitive treatment was institute at the Resuscitation Unit established in the main hospital. We found that following the earthquake, the CCS became clogged with the minor injured, makind triage more difficult and effective resuscitatioit impossible. The separation of Triage from Resuscitatio $\vec{\Omega}$ was a critical factor enhancing our ability to process many casualties. More than 450 patients were triage and treated in the CCS by 2 doctors and 3 nurses in the् first 14 hours. Of these, 152 were transferred $t \vec{E}$ Resuscitation for further treatment by 2 more doctors, of senior medical student and several medical orderlic우 Eighty-nine victims were eventually admitted to 융요 wards on the first day. The nature of structural dam especially to adobe buildings, and the resulting injugies encountered, accord well with those described follow earthquakes in other Third World countries $s^{2,3,8,11.12}$,

Large areas of relatively mountainous terrain affected by the earthquake, and helicopter evacua용 was crucial to successful casualty retrieval from isolxe communities. Sufficient aircraft may not be availablo $₫$ many third world countries. However, Royal Nepa Army helicopters evacuated a large number of patio․․유. in difficult weather conditions (Fig 9). This resulted sustained level of admissions over many days. Althoug numerically far fewer per day were treated tha immediately after the earthquake, the nature of th@ injuries became progressively more severe due t: neglect. This pattern of admission differentiates natur $\mathbb{B}$ catastrophies from other mass casualty situations suct as air disasters or train crashes ${ }^{13,14}$ and requires a long $\frac{\vec{\varphi}}{\text {. }}$ commitment to triage as each batch of rescued victims delivered to hospital (Table $6 \& 7$ ).

The air-portable military hospitals of many armi possess ideal qualities in both materiel and personnel respond to an earthquake. Their training in triage mass battle casualties is equally applicable to civilia natural disasters, and the surgical principles involved if the treatment of missile injuries are also appropriate t. the management of the major soft tissue wounds ang fractures encountered in earthquake victims. Adequat debridement, no primary closure and external fixatio요 of unstable open fractures with contaminated wound were all principles applied with great success to ol‥ patients. The use of military surgical (especiallno orthopaedic) teams in such circumstances has been reported in many previous disasters ${ }^{2,3.7}$. 


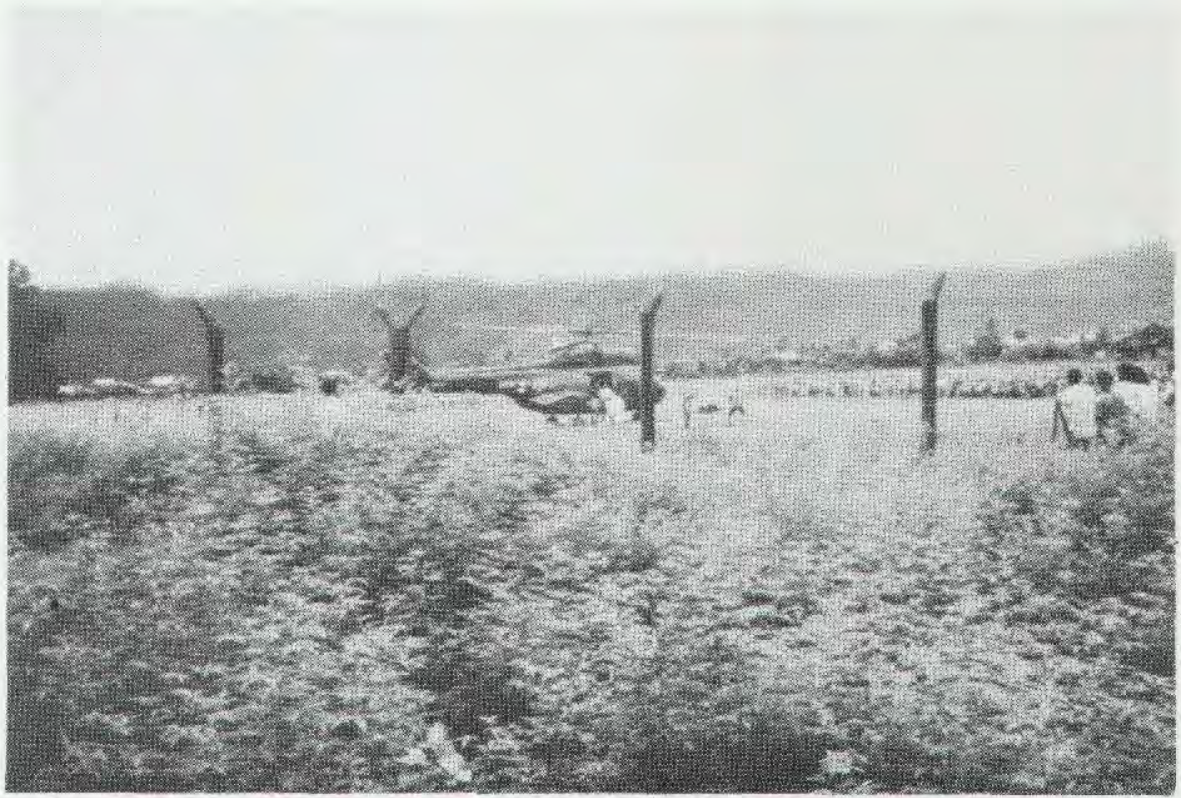

Fig 9. Royal Nepalese Army helicopter delivering a batch of victims. Note the hazardous flying conditions, with t to monsoon cloud base well down on the Himalayan foothills.

Reitherman ${ }^{15}$ pointed out that the construction of hospitals themselves renders them liable to be a major source of casualties in an earthquake. They are often large buildings with a high population density, and contain vulnerable machinery such as lifts, laboratory equipment and heavy plant such as boilers. Steinbrugge et $\mathrm{al}^{16}$ estimate that between $13 \%$ and $34 \%$ of all fatalities and serious injuries in the San Fernando Bay area of North America would be caused by damage to hospital buildings. Planning in earthquake zones should take account of these predictions, and hospitals should contain sufficient open ground to allow expansion into tented wards with triage and resuscitation areas. Although some hospitals were damaged in Nepal, we do not know of any fatalities or injuries that resulted. However, such damage severely curtailed local services in Dharan, adding particularly to our obstetric workload.
On occasions, our own specialist expertise art $\overrightarrow{0}$ operating theatre and intensive care facilities we under-used when poorer local civilian services we placed under extreme pressure. We found that tha apparent reluctance to transfer severely injured patiengon time for specialist treatment resulted in increas $\$$ morbidity and possibly mortality (Fig 10). These dela were in addition to those inevitably resulting fro collapsed buildings and disrupted communication Such hesitancy in accepting offers of both material aid and outside skilled medical assistance ${ }^{17}$ however, demonstrates that disaster relief can only be invited by $\stackrel{\varnothing}{\varnothing}$ and not imposed upon host governments. Nevertheless, $\overrightarrow{\vec{A}}$ the Armenian experience ${ }^{18,99}$ confirms the constructive $\frac{0}{3}$ international role that skilled medical personnel can play in the management of these severely injured patients. In many of the world's earthquake areas specialist units such as dialysis and orthopaedic teams

Table 6

Comparison of an earthquake and two rail disasters. The very large numbers of earthquake injured make triage and effective resuscitation more difficult, although a smaller proportion may be severely injured. Three individual hospita experiences.

\begin{tabular}{|c|c|c|c|}
\hline & $\begin{array}{c}\text { Nepal earthquake } \\
1988 \\
\text { BMH Dharan } \\
\end{array}$ & $\begin{array}{c}\text { Clapham rail } \\
\text { disaster } 1989 \\
\text { St Georges Hospital }^{13} \\
\end{array}$ & $\begin{array}{c}\text { Purley rail } \\
\text { disaster } 1989 \\
\text { Mayday Hospital }^{14} \\
\end{array}$ \\
\hline First day's casualties & $450+$ & 130 & 84 \\
\hline First day's admissions & $89(<20 \%)$ & $43(33 \%)$ & $39(46 \%)$ \\
\hline
\end{tabular}


must be brought to the patients if benefit is to be achieved.

Such benefits are not cheap, and when added to the cost of structural damage, few Third World countries can afford the price of the "high-tech" medicine and long-term rehabilitation required by many earthquakeinjured patients. A conservative estimate of the cost of Operation Nightingale is put at approximately $£ 0.4$ million. ( $£ 155,000$ for drugs and equipment, $£ 155,000$ for transport and movement of personnel and materiel, and $£ 90,000$ for reinforcing personnel costs.) Where death and disease are commonplace anyway, Third World governments may identify other priorities on which to spend such sums of money.

\section{Conclusions}

Disaster contingency planning is as important in the
Third World as elsewhere, although at the time of the East Nepal earthquake such plans were apparent lacking in civilian hospitals. Our experience at BM Dharan indicates that a well organized team of medic 8 and paramedical staff, however small, can respong effectively to the large number of casualties from ac earthquake, pending the arrival of medical reinforce? ments. Although the major accident plan for BM/ $\vec{F}$ Dharan was invaluable during the early phase of th? response, the magnitude of the disaster require considerable materiel and manpower enhancement the hospital. Ultimately, the effectiveness of the response is only as good as the infrastructure supporting it. Poverty in Third World countries may preclude the proper development of this critical infrastructure.

Under these conditions, natural catastrophies beg thit creation of sophisticated air-portable medical unit

Table 7

East Nepal Earthquake 1988 - Pattern of Admissions

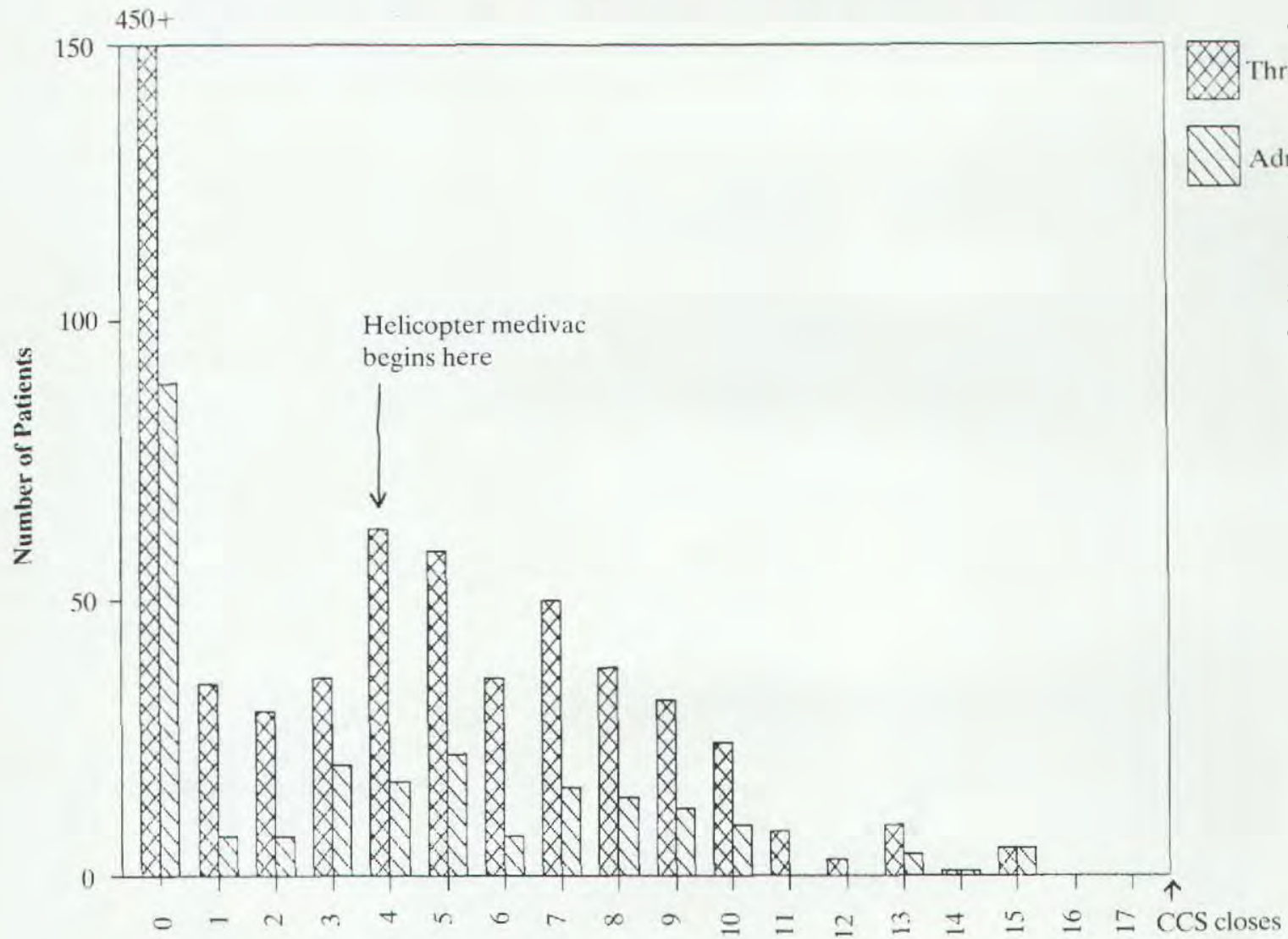

Days after Earthquake 


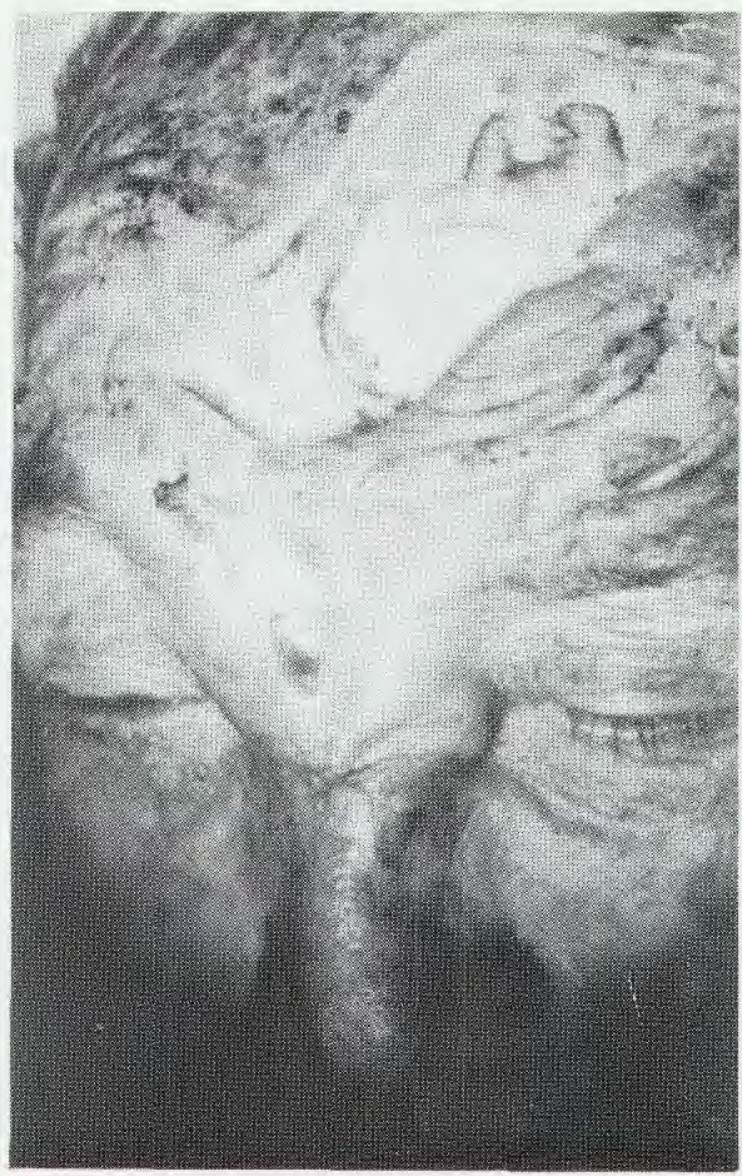

Fig 10. Untreated severe cranio-facial wound with underlying skull fracture, 8 days after injury. Patient died of tetanus 2 days after admission.

organized, staffed and adequately funded under the auspices of internationally acceptable agencies. Such units should exercise regularly under field conditions. Prompt arrival at the scene of the disaster is crucial if lives are to be saved, though in the context of an earthquake their role is probably better directed at the provision of specialist expertise and rehabilitation of survivors. Political factors may delay the arrival of such units until after their life-saving potential has expircd.

Good communications and leadership and a responsive re-supply chain are required to produce a rational and effective reply to a natural catastrophy, especially where medical teams are operational outside their normal areas. Following an earthquake, units sent in support of small hospitals must include orthopaedic facilities. ICU, obstetric and environmental health expertise may add considerably to the effectiveness of these emergency teams.

Many victims surviving an earthquake have severe orthopaedic injuries, but most of these can await the arrival of specialist expertise. Careful triage allow incumbent surgeons to salvage those with life threaten ing injuries. In these circumstances, we recommend tha triage, which can be performed by relatively inexperi $\mathbb{\AA}$ enced staff under supervision, should be carried out in an entirely separate area from resuscitation. The mos? severely injured patients can, after transfer, receive intensive treatment in resuscitation from doctor $\overrightarrow{\vec{C}^{*}}$ unencumbered by the hundreds of minor injure of clamouring for attention, distressed relatives, press an $\frac{2}{0}$ others.

Currently, air-portable military field hospital probably offer the best available facilities in response to natural disasters. Administrative and personnel officerê should accompany any sizeable contingent, especiall $\overrightarrow{0}$ when reinforcing a remote unit in the Third World.

Can one measure the value or effectiveness of $\vec{\omega}$ medical relief excrcise such as Operation Nightingale? One objective assessment was offered by Paul Bell Latin American Advisor, United States Office for Foreign Disaster Assistance (OFDA), who stated in hi report on the US earthquake relief programme:

"-the level of sophistication of the attention and surgery is comparable to that in London. What the British hi done in this hospital deserves our highest praise. In my years in responding to disasters, I have never seen? anything comparable."

\section{Acknowledgements}

The authors wish to acknowledge the crucial played by the Nepali staff of BMH Dharan and various departments of HQ British Gurkhas Nepal supporting the hospital. Without their expertise, and contribution from the conscripted wives of permanent staff, Operation Nightingale would not hä been possible.

Additionally, the authors wish to thank HM Kingू Birendra and members of the Nepalese Royal Family $\mathbb{8}$ Ministers of HM Government of Nepal and Seniog $\overrightarrow{\overrightarrow{0}}$ Nepalese Medical Staff, who frequently visited BMHB Dharan, and who permitted such an open policy of medical reinforcement with British military personnep and equipment.

\section{REFERENCES}

1. Dunnung F W, et al. The story of the Earth. HMSO 1981

2. WHITTACKER R, et al. Earthquake disaster in Nicaragua. I Trauma $1974 ; 14: 37-43$.

3. SHENG Z-Y. Medical support in the Tangshan earthquake. a review of the management of mass casualties and certaing major injuries. J Trauma 1987; 27: 10: 1130-5.

4. Beinin L. An examination of health data following twoo major earthquakes in Russia. Disasters 1981; 5:2: 142-46.

5. Seletz J M. Personal communication (Mannheim airo disaster)

6. Alexander D. Disease epidemiology and earthquake disaster. The example of Southern Italy after the 23 Nov 1980 earthquake. Soc Sci Med 1982; 16: 1959-69.

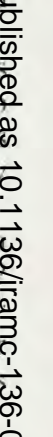


7. Leus $\dot{X}$. Natural disaster and communicable disease. Paper presented at the Symposium on Natural Disaster, Epidemiology and Environmental Health. 14-17 October, Havana, Cuba. 1985: 1-12.

8. MAHONEY L E. Catastrophic disasters, and the design of disaster medical care systems. Ann of Emergency Medicine 1987; 16:19: 1085-91.

9. Gilston A. Medical co-ordination during disasters. (Letter) Lancet 1985; ii: 895.

10. PATRICK J. A surgical thought on disaster relief. $\mathrm{Br}$ Med J 1988; 297: 1349 .

11. Berberian $M$ and Tabas-E-Golshan. Catastrophic earthquake of 16 September 1978. A preliminary field report. Disasters 1979; 2:4: 207-19.

12. GLASS R I, et al. Earthquake injuries related to housing in a Guatamalan village. Science 1977; 197: 638-43.

13. Stevens K L H. Personal communication. (Clapham Rail disaster.)
14. Hashemi K. Personal communication. (Purley Rats disaster.)

15. ReITHERMAN R. How to prepare a hospital for ar earthquake. J of Emergency Medicine 1986; 4: 119-31.

16. Steinbrugge K V, et al. Metropolitan San Francisco anch Los Angeles earthquake loss studies. 1980 assessment. $U$ 오 Geological Survey Open File Report 81-85. Denver, U. Geological Survey 1981 .

17. ROSSER N. Politics plague relief efforts. South Chin $\overrightarrow{\vec{A}}$ Morning Post. 12 Sep 1988.

18. RiChARDS N T, et al. Dialysis for acute renal failure due tif crush injuries after the Armenian earthquake. Br Med $1989 ; 298443-5$.

19. Colı.rvs A J. Kidney dialysis treatment for victims of thळ Armenian earthquake. N Engl J Med 1989; 320:19: 1291-2ఱ

20. Scotson D. (Defence Attaché, Kathmandu) Persona communication. 